\title{
Prospectiva del Derecho Administrativo en la era de la glocalización: el fin de la soberanía y el auge del soft law
}

\author{
Prospective of the administrative law in the era of glocalization: \\ the end of sovereignty and the rise of soft law \\ Perspectiva do direito administrativo na era da globalização: \\ O fim da soberania e o auge do soft law
}

\begin{abstract}
RESUMO
O presente artigo de refexão analisa duas categorias proprias da metodologia hermanêutica: as perpectivas e dinámica do direito administrativo no marco das transformações do estado, gerado pela dualidade global-local. $\mathrm{Na}$ análise perspectiva destaca-se nas novas dimensões que nessesariamente cria o fim do estado moderno e do conceito tradicional de soberania. Caracterizando o auge do soft law e novas formas de governanças.
\end{abstract}

PALAVRAS-CHAVES

Glovalização, Glo-cal, Estado social do direito, Tendências do direito administrativo, Soft law.

\section{RESUMEN}

El presente artículo de reflexión analiza dos categorías propias de la metodología hermenéutica: la prospectiva y dinámica cambiante del Derecho Administrativo en el marco de las transformaciones del Estado, generado por la dualidad global-local. En el análisis prospectivo se enfatiza en las nuevas redimensiones que obligatoriamente crea el fin del Estado moderno y de la concepción tradicional de la soberanía, caracterizando el auge del derecho suave y las nuevas formas de gobernanza.

\section{PALABRAS CLAVE}

Globalización, Glo-cal, Estado Social del Derecho, Tendencias del Derecho Administrativo, Soft law.

\section{ABSTRACT}

The reflection paper analyzes own categories of hermeneutics methodology prospective and changing dynamics of administrative law in the context of State transformations generated by the overall nonlocal duality. In the prospective analysis is emphasized in the new resizing it necessarily creates the order of the modern state and the traditional concept of sovereignty, characterizing the rise of soft law and new forms of governance.

\section{KEYWORDS}

Globalization, Glo-cal, social Rule of Law, Trends in Administrative Law, Soft law.

\section{EVER LUIS FERIA TOVAR}

Abogado egresado de la Universidad de Cartagena, especialista en Derecho Constitucional de UNISINÚ y especialista en Gerencia de Hacienda Pública de la Universidad CECAR. De igual forma, es candidato a Magíster en Derecho de la Universidad Sergio Arboleda. Actualmente se desempeña como notario segundo de Sincelejo. Este proyecto de investigación fue acompañado por la dirección temática y metodológica de Edimer Leonardo Latorre Iglesias, doctor en Sociología Jurídica e Instituciones Políticas. notariosegundodesincelejo@hotmail.com 


\section{INTRODUCCIÓN}

El Derecho administrativo del siglo veintiuno, el Derecho administrativo de la segunda modernidad, requiere una nueva piel, nuevas técnicas, nuevos instrumentos. Los administrativistas debemos ayudar a confeccionarla, no tratar de seguir enfundándolo en la vieja piel, una piel en muchos aspectos inservible, demasiado rígida y poco flexible (Puigpelat, 2004, pp. 245-246).

El dibujante Alex Raymond bosquejó en 1934 con el comic Flash Gordon (traducido al español como Roldan El Temerario), una sociedad intergaláctica, gobernada por una confederación planetaria que funciona como un solo mundo, con un solo ejército y con un objetivo fundamental: el consenso y la búsqueda de armonía que de él se desprenden. Este panorama utópico, propio de la ciencia ficción, se materializa cada vez más frente a las realidades actuales del mundo contemporáneo.

De ahí la abundancia de conceptos en el ámbito de las Ciencias Sociales que pretenden describir la interacción, velocidad y cambio constante que vivenciamos en nuestra realidad cotidiana: modernidad líquida (Bauman, 2010) que intenta explicar cómo los lazos y las convenciones sociales tradicionales se difuminan en la medida en que las fuerzas racionalizantes de la modernidad se apropian y colonizan los intersticios subjetivos de la vida social; sociedad postindustrial (Toffler, 2006) que tiende a precisar la característica de la vida actual, un mundo que deja de lado las chimeneas humeantes propias de la era fordista y da paso a la nueva era: el toyotismo, con un sistema basado en la hiperespecialización y la inversión de la pirámide organizacional, donde la clave es el cliente y el cambio para adaptarse a sus necesidades; era conceptual (Pink, 2008) que propone como base de la productividad la imperativa construcción de nuevas y claras formas de empatizar socialmente a través de la cocreación y la inteligencia colectiva. Se podrían citar otras denominaciones: era de las turbulencias (Greenspan, 2007), cibersociedad (Ohmae, 2008), sociedad postcapitalista (Drucker, 2002), o simplemente el mundo globalizado e hiperconectado (Castells, 2009).

En este sentido y a partir de la destacada abundancia conceptual que pretende aprehender las realidades veloces del mundo actual postmoderno, el comic con el que crecimos se puede estar convirtiendo en una profecía que se realiza, la interacción de los países por mediaciones altamente tecnologizadas se asemeja a la interacción de los planetas; hoy por hoy, posiblemente vivenciemos una sociedad transplanetaria, dado que estamos inmersos en un proceso imparable de globalización, que implica que lo local queda atrapado y subsumido en las fuertes e inmodificables tendencias globales.

De ahí que presenciemos cómo lo sagrado y profano de las sociedades antiguas, con su cortejo enmohecido de creencias, se di- 
suelve frente a nosotros (Marx, 1989), proceso que se resume en la famosa frase de Marshall Bergman (2011): "Todo lo sólido se desvanece en el aire". Vemos cómo cambian las formas tradicionales de la familia, de la propiedad, del tiempo y del espacio, y obviamente las transformaciones e hibridaciones que obligatoriamente asume el Estado y sus modelos de la gestión de lo público. El efecto de esta hiperconectividad salta a la vista: se revalúan los valores, se derrocan las tradiciones, se redefinen las instituciones y, particularmente, se rehace el Derecho.

El Derecho históricamente está en dinámica, en cambio, no es estático, obedece a una acción humana y a una modalidad de acción social, es decir, el Derecho es un hecho social y debe estar acorde con los cambios en los cuales él se desenvuelve. A este respecto, ya señalaba en su momento Ferrari (2006):

Estudiar el Derecho como modalidad de acción social significa indagar sobre las acciones humanas que en él se inspira, comprender su sentido y verificar si, y hasta qué punto, este es socialmente compartido, describirlas en su curso temporal, identificar sus efectos concretos y reconducir tales investigaciones a una visión teórica de conjunto que dé cuenta de la posición que en un ámbito de relaciones sociales recubre el derecho, visto tanto en su conjunto como en sus partes (p. 18).

Pero este Derecho que cambia, debe dar respuesta a los desafíos que implican las fuerzas particulares del fenómeno global, especialmente a la dicotomía conflictiva y en ocasiones excluyente de la relación globallocal, tal y como la plantea Robertson (2003). Esta disyuntiva exige una relación que implica pensar globalmente y actuar de manera local, o posiblemente, como lo plantea Bauman (2010), tenemos problemas globales que se materializan y exigen soluciones localmente.

La relación glocal hace que particularmente se redefinan tres grandes conceptos: el concepto de soberanía con sus tradicionales limitaciones geoespaciales, el concepto de Estado con su modelo de agenciar lo público, y especialmente el concepto de Derecho Administrativo, en la actual coyuntura, altamente vinculado al de gobernanza que implica un paso del hard law (derecho fuerte) al soft law (derecho blando) (Martel, 2012).

Si cambia la concepción tradicional del Estado y de agenciar lo público, debe cambiar el universo deóntico de lo jurídico, tal y como lo planteó en su momento el connotado analista Restrepo Medina (2002):

El Estado contemporáneo se enfrenta a un conjunto de desafíos que han puesto en tela de juicio las estructuras administrativas, la toma de decisiones de políticas establecidas y la forma de pensar acerca de la administración pública y del servicio civil, de lo cual se deriva un replanteamiento del papel que le compete cumplir y, por lo tanto, del régimen jurídico correlativo, 
máxime si se tiene en cuenta que los problemas que enfrentan los gobiernos no se reducen a la definición de medios operativos para su solución (p. 131).

Este cambio que da paso a un Estado regulador hace que el Derecho Administrativo se transforme, se ajuste y de una manera u otra enfrente tensiones entre el paso de un paradigma al otro. El histórico enfrentamiento entre lo público y lo privado (Arendt, 2005), la colonización del Derecho privado en la esfera del Derecho público (huida del Derecho Administrativo al derecho privado), la imposición de un Derecho internacional evitando las legitimaciones democráticas y especialmente la forma como se produce, crea y recrean los mecanismos de participación ciudadana, así como los procesos de despublificación o ius-privatización y la obligatoria necesidad de superar las disfunciones del modelo burocrático weberiano con los riesgos que presuponen las mentiras propias de un universo tecnocrático y racionalizador son las antinomias dialécticas actuales que asume el campo de tensiones que evidencia el Derecho Administrativo en el ámbito de lo glo-cal.

En el contexto praxeológico de estas tensiones se inscribe la pregunta problema que orienta este trabajo: ¿cuáles son las tendencias glo-cales que inciden en el reconfiguramiento del Derecho Administrativo en la contemporaneidad? Esto implica responder tres subpreguntas claves:
I) ¿Cuáles son las transformaciones del concepto de soberanía y de Estado que presenciamos en la actual coyuntura histórica?

II) ¿Qué reorganización y ajuste exige la tendencia del soft law a los Estados actuales?

III) ¿Cuáles son los retos del Derecho Administrativo en el fluctuar de lo glo-cal y en la redefinición de lo público?

Las respuestas a estas inquietudes se inscriben en un análisis teórico que asume dos vertientes. La primera de ellas defiende lo público como esfera autónoma que debe frenar los principios propios de un capitalismo inclemente y devorador que centrifuga lo público y lo cosifica a la esfera de lo privado y privatizador (Arendt, 2005; Ritzer, 2007; Piketty, 2014; Salden, 2013). La segunda vertiente defiende lo privado como una lógica racionalizante perfecta que debe eliminar lo público y sus defectos (Samuelson, 2004; Bell, 2004; Beck, 2008; Hayeck, 2008). Obviamente, se examinarán los desafíos del Derecho Administrativo como un Derecho que debe frenar el paso gigantesco y devorador no ya de la globalización, sino de la grobarización (Ritzer, 2007), que examina el lado oscuro de la globalización y lo categoriza como un proceso de licuefacción de lo público y su desaparición en lo global. Este artículo reflexivo propende por entender la forma como el Derecho Administrativo es el último baluarte que puede frenar la fuerza avasallante del capitalismo contemporáneo (Piketty, 2014). 
En este contexto teórico, diversos autores han trabajado sobre las diferentes formas y cambios que evidencia el Derecho Administrativo en el marco de la globalización. Uno de los autores que señala las diferentes evoluciones del Derecho en torno a los cambios del Estado es Juan Cruz Alli (2004), que ubica el nacimiento del Derecho Administrativo en la muerte del Estado absolutista y el afianzamiento de un Estado Social de derecho. Dicho de otra manera, el Derecho Administrativo surge en el núcleo básico de la Modernidad y del proyecto ilustrado, donde la clave es la idea de legalidad, de legitimidad, de equilibrio de poderes y de formación de ciudadanía, elementos que en la sociedad tecnocrática global pueden estar asumiendo nuevas formas y modalidades.

En este sentido, en su trabajo clásico sobre globalización, Estado y derecho, Mir Puigpelat (2004) analiza las transformaciones recientes del Derecho Administrativo, haciendo énfasis en las diferentes novedades del mundo global y de cómo los estados actuales, en permanente transformación, deben hacer frente desde lo público a fenómenos globales como la legitimación de sus procedimientos (gobernanza), las migraciones y la incidencia del capital transnacional y de las corporaciones que lo representan en las reconfiguraciones jurídicas de los órdenes regionales.

El jurista europeo Mariano Baena (2005) trabaja el problema de la racionalidad tecnocrática y de la eficiencia capitalista y cómo esta narrativa se ha erigido en una táctica para permear el Derecho público de una carga racionalizadora privativa. Este autor señala cómo el discurso del gerencialismo y la orientación a los resultados terminan siendo narraciones seductoras en Estados burocráticos y lentos para dar respuesta a las necesidades de sus colectivos, que no dejan entrever las limitaciones de la racionalidad técnica instrumental que son intrínsecas a su desarrollo.

En Colombia, es de exaltar la dedicación a la temática del doctor en Derecho Manuel Alberto Medina (2002), quien es creador de una línea de investigación sobre las tendencias del Derecho Administrativo y sus cambios en el modelo de Estado de la era global. Particularmente receptor de las tendencias teóricas europeas, su preocupación gira en torno a la defensa de lo público y a la maximización necesaria de la eficacia del Estado.

Sus premisas interpretativas propician un debate sobre los diferentes retos que debe enfrentar el Estado en la reorganización y adaptación de la gerencia de lo público a las exigencias del contexto local. De igual forma, un tema especial y relevante en las apreciaciones de este pensador es el llamado a revisar las diferentes implicaciones de la paulatina huida del Derecho Administrativo hacia el Derecho privado.

En esta misma línea se inscribe el aporte de Suárez Tamayo (2010), que examina un análisis de caso (los servicios públicos) que ubican 
de manera ejemplar los problemas e implicaciones de la huida del Derecho Administrativo hacia el Derecho privado. El enfrentamiento de estas dos lógicas -y la promoción para que la lógica privada se perciba como de mayor validez y eficacia- impide analizar los efectos de la concepción jurídica de lo privado en la gestión de lo público. Una de sus preguntas sigue vigente: ¿cuáles son los límites y controles frente a la huida del Derecho Administrativo para Estados precarios como el colombiano?

Brewer-Carias (2014) señala el deber ser del Estado frente a los peligros concomitantes del regreso de los Estados totalitarios, señalando que el Derecho Administrativo es propio de Estados Sociales de Derecho y que el proceso de constitucionalización que ha evidenciado es un síntoma de cómo se ha ido construyendo una jurisprudencia significativa frente a la temática. Es bastante sugestiva su afirmación de que:

Por ello, podemos responder a la pregunta sobre hacia dónde va el derecho público... afirmando que el mismo, en definitiva, va hacia donde vaya el Estado; y las nuevas tendencias del derecho administrativo serán las que resulten o se deriven de regular a la Administración de ese Estado; lo cual no deriva por supuesto de los solos enunciados constitucionales que a veces a lo único que nos conducen es a considerar el deber ser, es decir, lo que quisiéramos que fuera la tendencia del derecho admi- nistrativo, por supuesto, si el Estado fuera realmente, siempre, un Estado democrático (p.10).

Para realizar el abordaje y revalidar la pregunta de hacia dónde va el Derecho Administrativo -o, dicho de otra forma, ¿cuáles son las nuevas exigencias del ámbito global?-, este trabajo empleó metodologías propias de la hermenéutica jurídica, paradigma que se inscribe en el marco epistemológico del análisis hipotético deductivo, ya que se plantea la observación sistemática de un fenómeno, la construcción de una hipótesis explicativa del mismo, la sistematización de unas consecuencias o premisas derivadas y su verificación en el plano de la evidencia empírica.

Este marco epistemológico implicó el uso de la hermenéutica jurídica como método de comprensión y aprehensión de los fenómenos estudiados de una forma descriptiva. No se puede olvidar que la hermenéutica pretende comprender los fenómenos sociales tal y como lo afirma Packer (2010):

Nosotros, en tantos agentes sociales, siempre encontramos significado en un procedimiento, no al abstraer a partir de él una estructura lógica, sino al comprender a qué propósitos e intereses humanos sirve esa acción. La hermenéutica se ocupa del significado, como una sensibilidad que puede estar presente $o$ ausente en un proceder o en un recuento de esa acción (p. 12). 
La búsqueda de significaciones en torno a la forma como se producen las diferentes transformaciones del Derecho implica caracterizar las tendencias glocales que inciden en el reconfiguramiento del Derecho Administrativo en la contemporaneidad. Para ello se trabajarán tres grandes dimensiones en la estructura argumental del trabajo. En un primer momento, se persigue precisar las transformaciones del concepto de soberanía y de Estado que presenciamos en la actual coyuntura histórica. En un segundo aparte, se persigue delimitar la reorganización y ajuste de la tendencia del soft law a los sistemas jurídicos actuales. El trabajo finaliza con el proceso de analizar reflexivamente los retos del Derecho Administrativo en el fluctuar de lo glocal y en la redefinición de lo público.

\section{NUEVAS FORMAS DE SOBERANÍA: LAS MUTACIONES DEL ESTADO-NACIÓN EN LA ERA POSTMODERNA}

La firma de los tratados de Osnabruck y Munster (15 de mayo y 24 de octubre, respectivamente), en los territorios conocidos como de Westfalia, dio surgimiento al concepto (que teóricamente ya había sido planteado por Jean Bodino) del Estado-Nación. Los tratados de Westfalia materializan la idea de una integridad territorial como base del Estado y de una comunidad imaginada (en la visión de Anderson) como elemento clave de la formación de una Nación.

La Primera y especialmente la Segunda Guerra Mundial cambiarían el orden multipolar por un orden bipolar que daría la primera estocada de muerte a la paz de Westfalia. Ello conllevaría a la necesaria implementación de una sociedad de naciones, materializada en la Organización de las Naciones Unidas (ONU). Esta fungiría como elemento catalizador de las tensiones propias de las luchas territoriales. Aun en este modelo, los enfrentamientos estaban afincados en una versión colonial, donde lo importante era la anexión territorial y la dominación geoestratégica de territorios claves para un posible enfrentamiento bélico.

Con la caída del muro de Berlín, el 9 de noviembre de 1989 , se da inicio a un orden multipolar, donde paradójicamente ya no es necesaria la conquista estratégica de territorios y donde poco a poco surge una visión transnacional que derriba fronteras y acaba sistemáticamente con las concepciones jurídicas tradicionales de soberanía y Estado. En este orden multipolar, la característica es la creación de bloques económicos o de regiones comunes económicas, para homogeneizar sus Estados y su jurisprudencia, tal y como lo hemos podido verificar al hacerle seguimiento a la creación de la Comunidad Económica Europea, con todas las implicaciones políticas, sociales y económicas que padecen sus poblaciones (crisis española, crisis griega, modelo económico de subvención versus modelo económico de liberalización de la economía).

Con el auge de la creación del concepto de terrorismo global, se sepulta definitivamen- 
te el mundo creado por Westfalia, especialmente con la caída de las Torres Gemelas en el World Trade Center en New York, el 11 de septiembre de 2001, hecho que dinamiza la génesis de la doctrina del terrorismo global, fenómeno que evidencia las nuevas formas de interacción glocal: El nacimiento de una economía altamente interconectada donde, en tiempo real, el mundo está interaccionando e intercambiando bienes y servicios a solo un clic de distancia. En este sentido adquiere validez lo que ya señaló en su momento Suárez Tamayo (2010):

El Derecho administrativo global nace como una necesidad frente al aumento indiscriminado de organismos y regulaciones transnacionales que desbordan las capacidades normativas, de controles y responsabilidades de los Estados considerados individualmente, y de sus regímenes normativos internos. Sin lugar a dudas, la globalización lleva a una reducción de la autonomía normativa de los Estados, y al surgimiento y reconocimiento de nuevos centros de creación normativa (p. 291).

Lo que queda claro en la era actual es que, así cambien los órdenes globales y la geopolítica mundial, el concepto de soberanía y de Estado-Nación como lo conocíamos se ha difuminado, ya que sus delimitaciones conceptuales no posibilitan aprehender las realidades coyunturales actuales. En este sentido adquieren vigencia las críticas a las nuevas manifestaciones del fin de los Estados-Nación ya señalada por Hardt y Negri en su propuesta del concepto de imperio (2004):
En contraste con el imperialismo, el imperio no establece ningún centro de poder y no se sustenta en fronteras o barreras fijas. Es un aparato descentrado y desterritorializador de dominio que progresivamente incorpora la totalidad del terreno global dentro de sus fronteras abiertas y en permanente expansión. El imperio maneja identidades híbridas, jerarquías flexibles e intercambios plurales a través de redes de mando adaptables. Los colores nacionales distintivos del mapa imperialista del mundo se han fusionado y mezclado en el arco iris del imperio global (pp. 14-15).

Este imperio descentrado, desjerarquizado, altamente maleable y adaptable implica mutaciones en la idea tradicional de Estado. Como ya se había bosquejado, este concepto tiene sus orígenes en la visión de Maquiavelo que deslinda la política de la ética y de la moral, y la defiende como un escenario propio de la razón de Estado. Esta idea abstracta se ha ido nutriendo de otros aportes teóricos, especialmente de los argumentos que emanan de las visiones contractualistas de Estado, especialmente en la propuesta de monopolio de la violencia legítima y legal (Thomas Hobbes), y posteriormente en el de soberanía popular (Rousseau) y en el de equilibrio de poderes (Montesquieu).

Con la Revolución Francesa surge el Estado liberal, basado en un Estado Social de derecho que se estructura desde el paradigma de la Modernidad, donde los preceptos fundamentales son la materialización en la geren- 
cia pública de las libertades con un previo ejercicio democrático y una participación entendida en los parámetros de la ciudadanía propia del discurso ilustrado. Pero desde el surgimiento de este modelo de gestión de lo público se hace necesario diferenciarlo de la esfera privada, tal y como ya lo había planteado Habermas (1994) señalando lo público como la esfera del bien colectivo y la función pública como la defensa legítima y legal de estos intereses:

Privat alude a la exclusión de la esfera del aparato estatal; pues público tiene que ver con el Estado formado entretanto con el absolutismo, que se objetiviza frente a la persona del dominador. Das Publikum, the public, le public, lo público, es, en contraposición a la 'privacidad', el 'poder público'. Los servidores del Estado son personas públicas, öffentliche personen, public persons, personnes publiques; tienen un oficio público, los negocios de su oficio son públicos (public office, service publique), y públicos se llama a los edificios y establecimientos de la autoridad. Del otro lado está la gente privada,... los hogares privados... Enfrentados a la autoridad, están los súbditos excluidos de ella; aquella -se dice- sirve al bien común, éstos persiguen su provecho privado (p. 50).

Con el modelo de Estado de bienestar direccionado a cumplir con las promesas de las libertades y la promulgación de derechos sociales, el macro-Estado o Estado nodriza (Drucker, 2002) se implementa con éxito en
Europa y en la economía norteamericana. Este modelo entra en crisis con las encadenadas recesiones económicas, haciéndolo inviable desde el punto de vista financiero. Estas coyunturas decisivas dan paso a una renovación del modelo neoliberal de Estado con sus pretensiones: minimización del Estado, recorte de la economía del bienestar y huida del Derecho Administrativo al Derecho privado.

El tercer modelo de Estado toma fuerza en la contemporaneidad, propuesta que de una u otra manera matiza las imperfecciones del modelo neoliberal que entrega todas las regulaciones a la mano invisible del mercado, es por lo tanto la propuesta de un Estado regulador de riesgos la que hace frente al modelo neoliberal de Estado. La propuesta neoliberal, como lo ha señalado Piketty (2014), permite que el capitalismo se incremente de una forma abrumadora dado los márgenes de ganancia del capital patrimonial heredado.

Por ello, el Estado regulador de riesgos es un modelo que trata de conciliar las imperfecciones de las promesas incumplidas del neoliberalismo y controlar las formaciones económicas de trust y de posición dominante, tal y como lo plantea nuevamente Restrepo Mercado (2007):

Tal es el estado de cosas presente, frente al cual el propósito del presente escrito es presentar la manera en que los contenidos del Derecho Administrativo clásico, que 
responden a la teoría del servicio público del Estado intervencionista, se han adaptado para responder al modelo de Estado vigente, que ha pasado a ser un Estado regulador, que de prestador del servicio se ha convertido en garante de la prestación. Para tal efecto, debe considerarse que el modelo de Estado regulador tiene que resolver las tensiones que se presentan entre los intereses del mercado, propio de la prestación de los servicios ya no a cargo del Estado sino de los particulares, y los intereses de la ciudadanía, que responden a su papel activo como protagonista de su desarrollo en el Estado Social de Derecho, y por ello las respuestas dadas por el Derecho Administrativo a ese nuevo modelo de Estado en muchas ocasiones pueden resultar contradictorias (p. 5).

Por ende, los Estados actuales deben enfrentar estas dinámicas, particularmente una que ya había señalado Francis Fukuyama (2004), el problema de los Estados débiles en el marco de los órdenes geopolíticos globales. Señala este autor los límites de la acción estatal en la materialización de sus promesas y de sus obligaciones establecidas por el contrato social, pero al mismo tiempo la necesidad de lograr algo vital dentro del Derecho: la capacidad para materializar en el plano de la realidad el cumplimiento de la ley. Para este pensador el problema de lo público y de sus modelos de gestión estriba en entender las debilidades institucionales del Estado y las implicaciones, frente a otros Estados, de esta fragilidad institucional.
Por lo tanto, el planteamiento de Fukuyama replantea uno de los postulados básicos del neoliberalismo: la reducción del Estado. Hábilmente, Fukuyama sostiene que el problema no es el tamaño, sino la fuerza del Estado para materializar el imperio de la ley. En este sentido, son cuatro los aspectos claves que, interrelacionados sistémicamente, posibilitan una dinámica institucional efectiva en cuanto a la capacidad del Estado institucional para hacer sentir su existencia en la esfera de la vida pública y privada:

I) Diseño y gestión de la organización (estructura flexible y racional que posibilita eficiencia y eficacia).

II) El diseño del sistema político (distribución y garantía de los bienes políticos y del ejercicio de la ciudadanía).

III) La base de la legitimación (gobernanza y mecanismos garantizados de acción política colectiva e individual).

IV) Los factores culturales y sociales.

Considera este autor que los dos primeros factores se pueden aprender de otras realidades e innovaciones que Estados fuertes históricamente han logrado, lo que es difícil es que estas mejoras del Estado se transfieran a Estados débiles, dado que estos deberán enfrentar el problema de la gobernanza, pero especialmente el problema de los factores culturales y sociales. A pesar de lo obvio de que Colombia es un Estado débil o en vías de colapsar, se rescata de Fukuyama la necesidad de revisar la fuerza institucional que debe emanar del Estado. 
En este sentido, el trabajo de los economistas Daron Acemoglu y James Robinson (2012) aborda la problemática de forma innovadora, pues asumen el problema desde otra perspectiva. Para estos autores, el fracaso o éxito de un país no radica en sus políticas económicas, en su cultura, en su geografía o en sus políticos, sino en la fuerza de sus instituciones, las cuales pueden ser inclusivas o extractivas. En su estudio global de economías comparadas plantean lo siguiente:

Cada sociedad funciona con una serie de reglas políticas y económicas creadas e impuestas por el Estado y los ciudadanos colectivamente. Las instituciones económicas dan forma a los incentivos económicos: los incentivos para recibir una educación, ahorrar e invertir, innovar y adoptar nuevas tecnologías, etcétera. Es el proceso político lo que determina bajo qué instituciones económicas se vivirá y son las instituciones políticas las que determinan cómo funciona este proceso. Por ejemplo, las instituciones políticas de una nación determinan la capacidad de los ciudadanos de controlar a los políticos e influir en su comportamiento. Esto, a su vez, determina si los políticos son agentes (aunque sea imperfectos) de los ciudadanos, o si son capaces de abusar del poder que se les confía o que han usurpado, para amasar sus propias fortunas y seguir sus objetivos personales en detrimento de los de los ciudadanos. Las instituciones políticas incluyen constituciones escritas y si la sociedad es una democracia, pero no se limitan a ello. Incluyen el poder y la capacidad del Estado para regular y gobernar la sociedad. También es necesario considerar más ampliamente los factores que determinan cómo se reparte el poder político en la sociedad, sobre todo la capacidad de los distintos grupos de actuar colectivamente para conseguir sus objetivos o impedir que otras personas consigan los suyos. (Acemoglu; Robinson, 2012, p. 60).

Las instituciones inclusivas crean círculos virtuosos que en coyunturas críticas logran romper las cadenas del atraso y la miseria institucional. Uno de los grandes frenos es cuando el Derecho y la fuerza de cambio que este presupone son bloqueados por el poder de las élites. Cuando existe una percepción de que las normas son solo para un grupo especial de ciudadanos, esta percepción demuestra que estamos frente a un proceso de instituciones extractivas que únicamente preservan beneficios de élites y grupos de presión.

La clave frente a este problema es la mirada de lo público y la fuerza de las instituciones en la gerencia de la esfera pública. Para ello se necesita una coordinación entre la ciudadanía y las instituciones que logran movilizaciones en torno a lo político y a las visiones de sociedad. Estos círculos virtuosos inician cuando se logra llevar el Estado a todos los rincones del territorio. De lo contrario, transitaríamos lo que Robinson denomina como sociedad dual signada por zonas grises o vacíos alter-legales (2014): 
Colombia tiene una tradición de solidez democrática e institucional paralela a la guerra civil y al negocio de la droga debido a la manera particular en que el Estado colombiano se formó históricamente y se relacionó con su territorio y sus ciudadanos. Las elites nacionales en Bogotá jamás se propusieron controlar o regular vastas zonas del país, y en cambio delegaron dicha tarea a las elites locales, a cambio de votos en las elecciones. Esto generó una particular articulación geográfica del Estado, de los servicios estatales y del desarrollo. Hay un centro del país donde el Estado está más presente, las leyes y normas mejor ejecutadas y en el que hay menos pobreza; y hay una gran periferia en la que ocurre todo lo contrario. Tal periferia incluye la costa Caribe, los Llanos Orientales, el litoral Pacífico y las selvas y montañas del sur. La solidez institucional de Colombia se da en el centro. Si hay que hacer algo en Bogotá por medio de la Corte Constitucional o el Banco de la República, entonces puede funcionar. Si es necesario hacerlo en la periferia, como la reforma agraria, no funcionará. Parte de la clave para entender cómo lo funcional y lo disfuncional coexisten está en entender que los dos están espacialmente diferenciados. Que lo disfuncional esté en la periferia significa que el dolor y el caos que genera se concentran a gran distancia de las elites nacionales (p. 18).

Esta sociedad dual es la que hace que el país se perciba escindido, o posibilite que se ha- ble de dos países: una Colombia normativa y una Colombia real, o un país nacional y un país real. Estas dicotomías conflictivas alimentan la dinámica de violencia y lucha constante de nuestro país. Así mismo, nutren concepciones tradicionales que se enfrentan en el plano institucional.

La huida del Derecho Administrativo es también el repliegue del Estado y de la gestión de lo público y encubre una sistemática y radical forma de debilitar a las instituciones. Es decir, la radical colonización de lo público por las relaciones de mercado propias del modelo económico de mercado, hace que pasemos de una economía de mercado a una sociedad de mercado, signando comercialmente las relaciones entre el ciudadano (que se convierte en cliente) y el Estado (que se convierte en empresa).

Sandel ya lo había vaticinado cuando señalaba en su momento que el peor escenario era el ingreso de las relaciones de mercado en todas las dimensiones de la vida social: "La intromisión de los mercados, y del pensamiento orientado a los mercados, en aspectos de la vida tradicionalmente regidos por normas no mercantiles es uno de los hechos más significativos de nuestro tiempo" (Sandel, 2013, p. 15).

Visto así, el Derecho Administrativo que defiende lo público, y que es necesario para darle fuerza a las instituciones, fenece en la narrativa seductora de lo privado. Veamos las posibilidades que ofrece lo glocal de las 
nuevas formas de gobernanza en la defensa de lo público.

\section{DE LA ACCIÓN COLECTIVA CIUDADA- NA A LOS STAKEHOLDERS: EL AUGE DE LA GOBERNANZA Y EL SOFT LAW}

Una opción que ha hecho historia es propia del modelo del desarrollo equilibrado y armónico del capitalismo Renano, se puede afirmar que es un legado que se le ha dado al Derecho Administrativo. Nos referimos al concepto de stakeholders, que actualmente es vital para entender las tendencias del soft power y del soft law.

Los stakeholders son los grupos, organizaciones $u$ asociaciones que de una manera $u$ otra se interrelacionan con la acción empresarial. En la propuesta del capitalismo Renano, la deuda social de las empresas capitalistas es con los stakeholders y el núcleo como propuesta autorreguladora de un capitalismo voraz es la integración armónica de los grupos de interés con el desarrollo capitalista.

Las empresas deben integrarse con estas, en teoría, manifestaciones de la sociedad civil, integración que implica un diálogo de intereses y una solución de problemas comunes de forma consensuada, es decir, los grupos y asociaciones lograrían el equilibrio del capitalismo generando un capitalismo con sentido social. Este conjunto de postulados se materializa en la jurisprudencia de la Comunidad Económica Europea y en la integración jurídica que se construye entre los países que la conforman.
En la construcción del Libro Blanco que es la ruta política de la Comunidad Económica Europea, se ha estructurado un Derecho desde abajo (bottom up), jalonando la solución política a los problemas locales, permitiendo la construcción de soluciones desde los grupos de interés (stakeholders), es decir, se implica a los asociados comunes que, basados en un diálogo horizontal, deliberan las posibles soluciones a problemas locales. Desde los acuerdos y consensos construidos en este tipo de ejercicios, que se denominan propios del experimentalismo democrático, es donde aparece el derecho suave o soft law (Latorre, 2015).

Una de las promesas permanentes de este tipo de ensayos consensuales y deliberativos entre el Estado regulador, la empresa privada y la sociedad civil es la idea de una esfera deliberativa que produce consensos y que soluciona desde los interesados, problemas de una forma innovadora. Ya planteaba Tamayo Guisao (2015) las ventajas aparentes de estas formas de participación moderna:

Frente a la cada vez mayor deslegitimación del Estado y a la fuerza de la retórica jurídica que lo acusa por ineficiente, por desbordado, por obsoleto y por incapaz de materializar las deudas pendientes y las promesas postergadas, el fin del poder crea nuevos escenarios para la acción política de los colectivos y le da fuerza a la idea de una nueva ciudadanía que puede lograr en las plataformas virtuales y en la hiperconectividad nuevos armazones 
para hacer converger las ideas. Es en este marco de análisis, donde aparece la nueva utopía del capital social. Se importan conceptos foráneos como el de stakeholders (conocido como grupos de interés) y se apalancan en lo que surge de la acción colectiva de estos stakeholders, que debidamente orientada, produce un capital social, es decir, una fuerza que emana de lo social y puede generar transformaciones en lo social. Estos stakeholders se caracterizan por agruparse en redes, en grupos legales y especialmente en organizaciones no gubernamentales. La democracia experimentalista implica (deónticamente) una nueva gobernanza, un nuevo pacto social que se da en el marco de las sinergias del capital social, que nace a partir de una interacción deliberativa, indisoluble y que potencia interrelaciones creativas sustentadas en un aprendizaje mutuo, que se da entre actores con altos niveles de autonomía (stakeholders, ONG y redes organizadas en vínculos con el Estado) (pp. 106-107).

Lo que se infiere del análisis del sociólogo Tamayo Guisao (2015) es que existe una fuerte tendencia que se denomina fragmentación y difuminación del poder en microcentros o micropoderes que fluctúan de formas rápidas y redefinitorias propias del modelo de la modernidad líquida explicitado por Bauman, donde la indeterminación, polivalencia y multifuncionalidad dominan el centro de las relaciones de poder.
Visto así, no solo estaríamos frente al problema de la difuminación del Estado-Nación, sino que asistiríamos como espectadores de primera fila, al descentramiento del poder, tal y como ya lo había vaticinado el analista de la Revista Foreing Policy, Moises Naim (2013), cuando analiza cómo el poder ya no es lo que era.

Este autor señala cómo vivenciamos en nuestra cotidianidad nuevas formas de obtener el poder y nuevas formas de perderlo. Los movimientos de la primavera árabe que se dieron en torno a las dinámicas generadas a través de las redes sociales, o los cibermovimientos, los ocupy de Wall Street, los freeganos o la convergencia de la protesta social en las plataformas tecnológicas, demuestran que estamos frente a nuevas formas de obtener, preservar y transferir el poder. Naim precisa este nuevo escenario de la siguiente manera:

El poder se está degradando. En pocas palabras, el poder ya no es lo que era. En el siglo XXI, el poder es más fácil de adquirir, más difícil de utilizar y más fácil de perder. Desde las salas de juntas y las zonas de combate hasta el ciberespacio, las luchas de poder son tan intensas como lo han sido siempre, pero cada vez dan menos resultado. La ferocidad de estas batallas oculta el carácter cada vez más evanescente del poder. Por eso, ser capaces de comprender cómo está perdiendo el poder su valor -y de afrontar los difíciles retos que ello supone- es la clave para asi- 
milar una de las tendencias más importantes que están transformando el mundo en el siglo XXI (2013, p. 17).

De ahí que analicemos dos directrices contradictorias que chocan entre sí. Por un lado, los escenarios sociales del mundo actual necesitan un Derecho Administrativo centrado en la fuerza de la institucionalidad. Por otra parte, sin embargo, las tendencias obligan a una reconversión del poder, del Estado y obligatoriamente aparejado, la subsunción del Derecho Administrativo y la gobernanza que lo legitima, a las lógicas deónticas de la economía de mercado.

Esta afirmación se hace en el contexto de análisis glocal, puesto que la propuesta del soft law que se atrinchera en la tendencia del soft power -y que es el epítome ideal de la gobernanza- encierra una exclusión: la elitización paulatina de los stakeholders que son cooptados por grupos de poder y grupos de presión con la fuerza económica necesaria para ocupar los escenarios propios de la deliberación y de la argumentación, y así posibilitar las propuestas y soluciones de los grupos de interés.

Es decir, este modelo Renano de administración del Derecho público desde la gobernanza termina atrapado por las lógicas racionales de lo privado que promocionan los stakeholders más poderosos, con mayor posibilidad de argumentar, con mayor probabilidad de asumir el control económico por los recursos con que cuentan y dado el poder que se puede manejar frente a los medios masivos de comunicación. Mercado (2012) plantea las antinomias entre los modelos de lo público y de lo privado contenidos en estos dos enfoques del Derecho público y sus retóricas jurídicas:

Nos sitúa ante una nueva retórica jurídica, simbólicamente representada por la contraposición de los imaginarios del hard law y del soft law, paradigmas contrapuestos acerca de la creación de las normas jurídicas, de sus características formales, o de sus formas de aplicación y control: así, frente a un derecho creado vertical y jerárquicamente a través del monopolio de autoridad pública, una creación del derecho horizontal, participativa, consensuada y deliberativa; frente a un derecho aplicado mediante la imposición de deberes, penas o sanciones por el Estado, por el órgano administrativo o por el juez correspondiente, un modelo de aplicación del derecho basado en incentivos, en códigos voluntarios, en informaciones técnicas o basadas en los mercados, en evaluaciones comparativas y en el aprendizaje mutuo y la rendición de cuentas (2012, p. 46).

Se insiste, la narración jurídica plantea que hay una nueva gobernanza, pero lo que evidencia la tendencia es que la gobernanza solamente es para unos seleccionados, es decir personas o grupos que poseen las condiciones para deliberar, pero estas condiciones no son normativas, no están en el marco de los derechos, son condiciones que única y exclusivamente giran en torno a lo económico. 
Visto así este panorama, se puede precisar que las tendencias glocales encubren de una forma seductora las celdas propias del capitalismo global. El objetivo al final es el desmembramiento del Derecho Administrativo y la preeminencia del Derecho privado, el recorte del Estado y la gestión de lo público con características de lo privado.

Por ende, la prospectiva señala que existe una lucha entre el Derecho Administrativo, la defensa del interés colectivo y las realidades glocales. La participación necesaria para la defensa de lo público también termina difuminándose, Boaventura de Souza y César Rodríguez Garavito lo plantean de esta manera:

Acepta la ecuación, pero bajo la condición de reemplazar la participación autodeterminada con una participación basada en un principio de selección, según el cual se escogen algunos actores, intereses y voces para que participen, mientras otros se dejan por fuera. Puede que los participantes sean independientes, pero no lo son los criterios mediante los que se seleccionan los participantes. Puede que aquellos que han sido escogidos para participar se beneficien de ello, pero siempre a costa de aquellos que quedan fuera de la participación. La ecuación está, por lo tanto, desradicalizada e instrumentalizada (2007, p. 37).

En este contexto analítico, la gobernanza y sus tan aclamados espacios participativos pueden ser mascaradas de participación ciu- dadana que buscan legitimar a los gobiernos de turno. En ese sentido, se combatiría la idea de democracia, básica para la legitimidad institucional y el funcionamiento del Derecho Administrativo, con ideas que propenden por ser democráticas. Explicado de otra forma, una democracia de gobernanza termina siendo una antidemocracia.

Es claro e innegable que el Derecho Administrativo debe entender estas dinámicas, ajustarse y flexibilizarse, pero no puede perder la esencia que lo constituye, el apego a un estado que garantiza los derechos fundamentales, es decir el apego a la idea clásica con la que se da la génesis del derecho Administrativo: el Estado Social de Derecho. Es bien interesante señalar cómo ya el año 2002, Restrepo Medina, había explicado esta disyuntiva y sus implicaciones:

Esta complejidad, vista desde el derecho administrativo, se manifiesta en una mezcla de objetivos que van desde el puro afianzamiento del Estado de derecho y su defensa frente a amenazas de los más variados actores, pasando por la afirmación de la responsabilidad del Estado, el fortalecimiento del principio de legalidad y del respeto a los derechos ciudadanos, la introducción de elementos de participación ciudadana que superen el simple discurso, hasta el necesario replanteamiento de la capacidad reguladora del Estado y de la noción de servicio público, en un contexto de mundialización y libre competencia y la aclimatación y el acompañamiento jurídi- 
co del uso de nuevas tecnologías e instrumentos de gestión que intente el diálogo entre gestión y derecho (2002, p. 133).

Nótese la parte final, el diálogo entre gestión y derecho. Diálogo implica apertura, reconocimiento y deliberación entre iguales y no lo que está sucediendo en la actualidad: no existe diálogo sino subsunción, cosificación e instrumentalización. Los retos no solo están en los ajustes que los Estados deben hacer al Derecho Administrativo, sino en la defensa del Derecho Administrativo frente a las fuerzas centrifugadoras y alienantes del capitalismo neoliberal. De ahí que el Derecho Administrativo pueda ser el inicio de las barricadas simbólicas que detengan o al menos ajusten el Derecho a su capacidad transformadora de la realidad.

\section{CONCLUSIONES}

Las pretensiones de este artículo de reflexión giran en torno a la comprensión de las tendencias del Derecho Administrativo en la manifestación de la globalización en los escenarios locales. Por ello se explican los cambios y difuminaciones de los tradicionales presupuestos teóricos del Estado-Nación, las transformaciones que aún vivencia el Estado y su intento por convertirse en un Estado regulador de riesgos.

De igual forma, se logra dibujar un mapa prospectivo de las racionalizaciones instrumentales que conlleva la tendencia del soft law y sus seductoras narrativas materializa- das en el concepto de stakeholders, señalando cómo las lógicas capitalistas privatizadoras pueden adueñarse y cooptar estas formas de legitimar el funcionamiento del Estado. De igual forma, el artículo logra plasmar las tensiones entre lo público y lo privado, entre el Derecho Administrativo y su huida hacia el Derecho privado. En el fondo de estas tendencias mundiales, sigue vigente la lucha por un Derecho Administrativo que defienda lo público.

Frente a esta defensa, está la necesaria fuerza de las instituciones que determina el éxito o fracaso de un país. De ahí que se logre plantear la necesidad de reconfigurar el Estado, centrándose no en su tamaño, sino en su fuerza y en el carácter inclusivo que asuman sus instituciones.

Queda pendiente para el Derecho Administrativo la tarea de pensar y repensar la búsqueda de una ciudadanía participativa, instruida y particularmente capaz de tomar decisiones políticas que logren implementar políticas públicas en el marco de las esferas deliberativas propias de la ciudadanía moderna. Tarea que en Colombia aún está pendiente por hacer.

\section{REFERENCIAS}

Acemoglu, D. \& Robinson, J. (2012). El fracaso de las naciones. Barcelona: Deusto.

Anderson, B. (1993). Comunidades imaginadas. México: Fondo de Cultura Económica. 
Arendt, H. (2005). La condición humana. Barcelona: Paidós.

Baena del Alcazar, M. (2005). Manual de ciencia de la administración. España: Síntesis.

Bauman, Z. (2010). Modernidad líquida. Buenos Aires: Fondo de Cultura Económica.

Beck, U. (2008). ¿Qué es la globalización? Falacias del globalismo, respuestas a la globalización. Madrid. Paidós.

Bell, D. (2004). Las contradicciones culturales del capitalismo. Madrid: Alianza.

Bergman, M. (2011). Todo lo sólido se desvanece en el aire. Buenos Aires: Siglo XXI.

Brewer-Carias, A. (2014). Estado totalitario y nuevas tendencias del derecho administrativo. Bogotá: Universidad del Rosario.

Castells, M. (2009). Comunicación y poder. Madrid: Alianza.

Cruz Alli, J. (2004). Derecho administrativo y globalización. Madrid: Civitas.

De Sousa Santos, B. \& Rodríguez Garavito, C. (eds.) (2007). El derecho y la globalización desde abajo. Hacia una legalidad cosmopolita. Barcelona: Anthropos Editorial.

Drucker, P. (2002). La gerencia en la sociedad futura. Bogotá: Grupo Editorial Norma.
Ferrari, V. (2004). Derecho y sociedad: elementos de sociología del derecho. Bogotá: Universidad Externado de Colombia.

Fukuyama, F. (2004). La construcción del Estado: hacia un nuevo orden mundial en el siglo XXI. Barcelona Ediciones B.

Greenspan, A. (2007). La era de las turbulencias: aventuras en un nuevo mundo. Barcelona: Ediciones B.

Greenspan, A. (2008). La era de las turbulencia: aventuras en el nuevo mundo. Barcelona: Ediciones B.

Habermas, J. (1994). Historia y crítica de la opinión pública. Barcelona: Ediciones G. Gilli.

Hardt, M. \& Negri, A. (2004). Imperio. Barcelona: Paidós.

Hayeck, A. (2008). Camino a la servidumbre. México: Fondo de Cultura Económica.

Latorre Iglesias, E. L. (2015). Litigio estructural e ingeniería jurídica. Bogotá: Fondo de Publicaciones Universidad Sergio Arboleda.

Martel, F. (2012). Cultura Mainstream. Barcelona: Taurus.

Marx, K. (1989). El manifiesto del Partido Comunista. Barcelona: Bruguera.

Mercado Pacheco (2012). Experimentalismo democrático, nuevas formas de regulación y legitimación del derecho. Granada: Universidad de Granada. 
Naim, M. (2013). El fin del poder: empresas que se hunden, militares derrotados, Papas que renuncian, y gobiernos impotentes. Cómo el poder ya no es lo que era. Barcelona: Debate.

Ohmae, K. (2008). El próximo escenario global: desafíos y oportunidades en un mundo sin fronteras. Bogotá: Grupo Editorial Norma.

Packer, M. (2010). La investigación hermenéutica en el estudio de la conducta humana. En http://www.psicologiacultural.org/ Pdfs/Traducciones/La\%20investigacion\%20 hermeneutica.pdf

Piketty, T. (2014). El capitalismo en el siglo XXI. México: Fondo de Cultura Económica.

Pink, D. (2008). Una nueva mente. Madrid: Ilustrae.

Puigpelat, Oriol Mir (2004). Globalización, Estado y derecho. Las transformaciones recientes del derecho administrativo. Barcelona: Thomson Civitas.

Restrepo Medina, M. A. (2002). La adecuación del derecho administrativo al Estado contemporáneo. Revista Estudios Socio-jurídicos, 4(2), 130-153. Octubre. Bogotá: Universidad del Rosario.

Ritzer, G. (2007). La globalización de la nada. Barcelona: Popular.
Robertson, R. (2003). Globalización, tiempoespacio y homogeneidad-heterogeneidad: problemas políticos de la mundialización. Madrid: Trotta

Robinson, J. (2014). La realidad colombiana. En M. T. Ronderos, Guerras recicladas. Bogotá: Aguilar.

Salden, M. (2013). Lo que el dinero no puede comprar: los límites morales del mercado. Madrid: Debate.

Samuelson, P. (2004). Economía. México: McGraw-Hill.

Suárez Tamayo, D. (2010). Huida o vigencia del derecho administrativo: el caso de los servicios públicos domiciliarios. Transformaciones-tendencias del derecho administrativo. Medellín: Universidad de Antioquia.

Tamayo Guisao, E. J. (2015). Participación ciudadana y democracia experimentalista. Tesis de grado. Medellín: Universidad Pontificia Bolivariana.

Toffler, A. \& Toffler, H. (2006). La revolución de la riqueza. Barcelona: Debate.

Von Hayek, F. (2011). Camino de servidumbre. Madrid: Alianza. 